\title{
Article
}

\section{Analysis and Modeling for Cold Chain Logistics of Agricultural Prod- ucts Demand Forecasting}

\author{
Siyuan Wen ${ }^{1}$, Jiankun $\mathrm{Li}^{2}$, Rui Wang ${ }^{3}$ and Hao Liu ${ }^{4, *}$ \\ 1,2,3 Shandong University of Finance and Economics , Jinan 250014, China. \\ ${ }^{4}$ Shandong Jianzhu University, Jinan 250014, China. \\ 1 Affiliation 1; siyuan@ sdufe.edu.cn \\ 2 Affiliation 2; jiankun @sdufe.edu.cn \\ 3 Affiliation 3; wangrui @sdufe.edu.cn \\ 4,* Correspondence: 15953119723@139.com
}

\begin{abstract}
Cold chain logistics of Agricultural Products demand forecasting can provide the scientific basis for the country to formulate logistics strategy, which further promotes the development of social economy and the improvement of living standards in China. In this paper, a new mathematical combined model is proposed to Agricultural Products Demand. Shandong, one of a China's province, serves as the main producer and distributor of agricultural products. Based on the index system created from multiple related factors influencing cold chain logistics demand of agricultural products in Shandong, this paper employs principal component analysis to reduce the dimension of various indexes and predicts principal components with time series. Thereafter, multiple linear regression model and neural network model were constructed to forecast the cold chain logistics demand of agricultural products in Shandong, and their combined forecast models were compared. What's more, the paper provides insight for reference and decision-making concerning the development of cold chain logistics industry of agricultural products in Shandong province.
\end{abstract}

Keywords: cold chain logistics of agricultural products; demand forecast; principal component analysis, multiple linear regression, neural network.

\section{Introduction}

Nowadays, the change of people's ideas and the prosperous market economy have spawned an emerging circulation system of agricultural products, and a market focusing on high-quality and efficient agricultural products transportation and benign scale economy has gradually taken shape. The products transportation, circulation and other links of traditional agriculture can no longer satisfy modern market, not to mention people's pursuit of quality products. The rapid development of cold chain logistics caters to people's mounting demand for eggs, milk, fresh fruits and vegetables, etc., while posing challenge to China's relatively backward cold chain logistics. As a latecomer, China's coldchain logistics of agricultural products develops fast and has made some achievements, but still far back on that of developed countries. Therefore, it's imperative to advance its development[1].

Cold chain logistics of agricultural products can improve the efficiency and quality of the whole logistics process from production to sale in Shandong, a main producers and consumers of agricultural products, and benefit local farmers, such as increasing farmers' income, protecting farmers' interests, and improving the lives of urban and rural residents. Considering the immature local cold-chain logistics industry, how to accelerate the healthy development of cold-chain logistics for agricultural products in Shandong remains an important and urgent issue[2].

In recent years, the cold chain logistics of agricultural products has caught the attention of the state and local governments. Development Plan of Cold Chain Logistics for Agricultural Products issued by National Development and Reform Commission has made a plan for the development of cold chain logistics for agricultural products in 
China[3]. The main tasks, key projects, safeguard measures and other policy planning concerning China's agricultural cold chain logistics ensure a favorable environment. At the same time, local governments including Shandong provide various subsidies for related infrastructure construction, which also reduces cost, and the key support for coldchain logistics system in key regions promotes its rapid development. Given the favorable development environment and strong demand in Shandong, the demand forecast of cold chain logistics for agricultural products provides quantitative reference for decision-making and deployment concerning cold chain logistics industry of agricultural products to a certain extent, thus realizing its healthy and sustainable development.

In view of the fact that most products employing cold-chain logistics in China belong to primary agricultural products, this paper takes agricultural products, covering fruits, vegetables, aquatic products, meat, eggs, milk, etc., as the main research objects[4]. Studies on cold chain logistics of agricultural products in China has been carried out extensively in recent years, with analysis on basic theory and current situation dominating. For example, Huang Liwei [5] clarified in detail the agricultural product cold chain logistics related concepts, and analyzed the current situation and main problems of agricultural product cold chain logistics in China by using a large amount of data based on relevant theories, and then put forward relevant suggestions. Xu Qian, Zhao Min [6] made field visits and investigations, made in-depth analysis of the current development status of the agricultural product supply chain in Shandong Province in combination with theoretical analysis, and discussed its existing problems, and put forward relevant guidance and suggestions; in terms of demand forecasting, He Guohua et al. [7] espectively forecasted the regional logistics demand by using grey forecasting analysis method, multiple regression linear model, and trend extrapolation method. Yan Juan [8] studied the application of gray neural network model in logistics demand forecasting, and illustrated the reliability of the combined forecasting method. Wang Shaoran [9] took the cold chain logistics of fresh agricultural products as the research object, analyzed the factors affecting the cold chain logistics demand of fresh agricultural products, and constructed a non-linear combination forecasting model based on SVR to forecast the demand. Wang Xiaoping and Yan Fei (2018) constructed a GA-BP neural network model for predicting the cold chain logistics demand of agricultural products and predicted the urban agricultural cold chain logistics demand in Beijing.

In terms of cold chain logistics of agricultural products and related forecasting, foreign researches started early and were gradually improved, with plenty of research achievements. In terms of the research of cold chain logistics theory, Albert Barrier used the concept of cold chain for the first time; American scholars Assad, Zoll and et al. respectively proposed 3T, 3P, 3C theories in 1985, including the freezing time, storage tolerance and storage temperature of food and etc.; From the perspective of cold chain logistics management, Bojataj [10] and et al. deeply studied the impact of changes in supply chain such as time, distance and temperature on the stability of perishable products. Montanari $\mathrm{R}$ [11] proposed a structured framework to determine the most suitable solution and minimize logistics costs in order to ensure the quality of cold chain food in the supply chain. Ran [12] et al. analyzed the application status of cold chain logistics in the field of agricultural products, explored the impact of cold chain logistics on the costs and benefits of agricultural products in China in quantitative and qualitative analysis methods and proposed improvement measures.

In terms of research on cold chain logistics practice, James suggested adopting appropriate packaging boxes and advanced transportation equipment in order to reduce the loss of frozen food in the circulation process. Abou (1997) and et al. believed that the natural growing environment and climatic conditions of agricultural products have varying degrees of influence on the production quantities. K.Likar [13] made investigation on cold chain retail market and the import and export of stores and made an in-depth research on cold chain interruption and quality management and the like problems in food trade based on the investigation. Kim [14] et al. designed an algorithm for good temperature and humidity levels in cold storage and applied it to facilities storing perishable products, 
and introduced a standard for evaluating the quality of fresh vegetables. Bin Z [15] et al. planned and studied the cold chain logistics park of agricultural products, and carried out scientific and reasonable planning for cold chain logistics and storage of agricultural products to reduce cold chain costs.

With respect to the demand forecasting methods, Fanlk [16] and et al. studied some combination forecasting methods. The extensive use of combination forecasting methods made great progress in the field of demand forecasting. Flsieh [17] forecasted the cold chain logistics demand of agricultural products based on relevant indicators such as the supply and demand of fresh agricultural products, and gave relevant opinions on the supply and demand of cold chain logistics of agricultural products. Nuzzolo [18] proposed a model system that comprehensively considers liquidity and restocking, and forecasted the urban logistics demand. Can Eksoz [19] et al. used BP neural network method to forecast the demand of agricultural products, compared it with gray forecast linear regression and other methods, and analyzed the superiority of neural network forecasting.

Therefore, through careful comparison, this paper selects many factors affecting cold chain logistics of agricultural products in Shandong, and establishes demand forecasting index system from various angles, so as to carry out demand forecasting more comprehensively and accurately. Principal component analysis, a common method for dimension reduction, can reduce the dimension of numerous index data and convert them, which is beneficial to the following data prediction. Multiple linear regression model and neural network model were constructed based on principal component index and cold chain logistics demand data of agricultural products. The combined prediction model enjoys both the scientific simplicity of linear regression and the accuracy and reliability of neural network. Time series also make the prediction of principal component more accurate, thus achieve the purpose of prediction through principal component.

\section{Analysis of influencing factors and establishment of index system}

2.1. Source of index data

The factors affecting the demand for cold chain logistics of agricultural products in Shandong involve economy, society, agriculture and so on. In this paper, representative influencing factors will be selected from various aspects as indicators to establish an index system, which guarantees a more comprehensive prediction of cold chain logistics demand of agricultural products in Shandong. At the same time, the availability of data is also taken into account to select suitable index data. Relevant data are mainly obtained from Statistical Yearbook of Shandong Province, Statistical Yearbook of China, and National Bureau of Statistics. Direct reference or indirect calculations of data on the network are also included.

No demand index for cold chain logistics of agricultural products is found among statistical tables or data tables concerning Shandong. However, considering that the demand for agricultural products can serve as a reference for the demand for cold chain logistics of agricultural products to some extent, this paper takes the number of permanent residents * per capita consumption of agricultural products in Shandong as the demand for cold chain logistics of agricultural products, among which per capita consumption of agricultural products is the sum of the demand for major agricultural products including fruits, vegetables, meat, eggs, aquatic products and dairy products[20].

Analysis of influencing factors on demand forecast of cold chain logistics of agricultural products in Shandong

Many factors should be covered in demand forecast of cold chain logistics of agricultural products in Shandong. According to the development of cold chain logistics of agricultural products in Shandong in the past two decades, the market supply and demand, and relevant theoretical research inside and outside China, the demand system of cold chain logistics of agricultural products is complex and comprehensive. Based on available data from 2001 to 2019 and influencing factors such as economy, society and logistics, the 
influencing factors can be summarized and selected, which fall into the following four camps:

Economy: The cold chain logistics industry is greatly affected by economy, and so is cold chain of agricultural products. More developed economy leads to broader market and more demand. What's more, the development of all kinds of industries will affect the demand for cold chain of agricultural products. Therefore, regional GDP, the added value of the primary industry, the added value of the secondary industry and the added value of the tertiary industry were selected as forecast index as for economy.

Society: Social factors, especially humanistic factors, exert huge impact on cold chain logistics of agricultural products. In view of the demand for cold chain logistics of agricultural products is directly influenced by population scale, per capita consumption of agricultural products, and people's requirements on the quality of agricultural products, two indexes, permanent resident population at the end of the year and total retail sales of consumer goods, are selected.

Agriculture: The production of agricultural products can meet the market demand, resulting in the demand for cold chain logistics of agricultural products. The balance of supply and demand among all agricultural products also continuously affects the change of demand for cold chain logistics. In addition, the price of agricultural products directly sways the purchase intention of consumers, thus affecting the demand for cold chain logistics. Therefore, the production price index of agricultural products and fruit and vegetable output are selected[21].

Logistics: The existing logistics restricts the development of cold chain logistics. The scale of logistics industry, logistics infrastructure and logistics transport capacity are all factors affecting cold chain logistics. The demand for cold chain logistics of agricultural products is closely related to the comprehensive situation of logistics. Therefore, the freight volume and turnover of Shandong are selected as forecast index.

Establishment of demand forecast index system for cold chain logistics of agricultural products in Shandong

After the analysis and comparison of various indicators and the availability of data, this paper selects relevant index data of Shandong from 2001 to 2019 as samples to predict the demand for cold chain logistics of agricultural products in Shandong. The definition of each index is as follows:

$\mathrm{Y}$ refers to the demand for cold chain logistics of agricultural products (10,000 tons)

$\mathrm{X}_{1}$ refers to regional GDP (100 million yuan)

$\mathrm{X}_{2}$ refers to the added value of the primary industry (100 million yuan)

$\mathrm{X}_{3}$ stands for the added value of the secondary industry (100 million yuan)

$\mathrm{X}_{4}$ stands for the added value of the tertiary industry (100 million yuan)

$\mathrm{X}_{5}$ stands for the permanent resident's population at the end of the year $(10,000$ people)

$\mathrm{X}_{6}$ serves as the total retail sales of consumer goods (100 million yuan)

$\mathrm{X}_{7}$ serves as the production price index of agricultural products

$\mathrm{X}_{8}$ serves as the output of fruits and vegetables (10,000 tons)

$\mathrm{X}_{9}$ serves as the freight volume of Shandong Province (10,000 tons)

$\mathrm{X}_{10}$ serves as the turnover (million tons $/ \mathrm{km}$ )

Table1. Demand for cold chain logistics of agricultural products and its influencing factors in Shandong province from 2001 to 2019 


\begin{tabular}{|c|c|c|c|c|c|c|c|c|c|c|c|}
\hline Variable & $\mathrm{Y}$ & $\mathrm{X}_{1}$ & $\mathrm{X}_{2}$ & $\mathrm{X}_{3}$ & $\mathrm{X}_{4}$ & $\mathrm{X}_{5}$ & $\mathrm{X}_{6}$ & $\mathrm{X}_{7}$ & $\mathrm{X}_{8}$ & $\mathrm{X}_{9}$ & $\mathrm{X}_{10}$ \\
\hline 2001 & 3918.71 & 9195.04 & 1359.49 & 4556.01 & 3279.53 & 9041.00 & 2834.90 & & & 101775.00 & 4693.10 \\
\hline 2002 & 3936.48 & 10275.50 & 1390.00 & 5184.98 & 3700.52 & 9082.00 & 3181.90 & & & 110185.00 & 4149.20 \\
\hline 2003 & 3955.12 & 12078.15 & 1480.67 & 6485.05 & 4112.43 & 9125.00 & 3936.50 & 108.50 & 11255.27 & 117051.00 & 3908.90 \\
\hline 2004 & 3978.96 & 15021.84 & 1778.45 & 8478.69 & 4764.70 & 9180.00 & 4483.40 & 112.30 & 11362.20 & 129024.00 & 4752.50 \\
\hline 2005 & 4008.43 & 18366.87 & 1963.51 & 10478.62 & 5924.74 & 9248.00 & 6166.90 & 102.90 & 11153.82 & 144701.00 & 5551.00 \\
\hline 2006 & 4034.87 & 21900.19 & 2138.90 & 12574.03 & 7187.26 & 9309.00 & 7217.10 & 103.40 & 10539.81 & 164132.00 & 6387.40 \\
\hline 2007 & 4060.01 & 25776.91 & 2509.14 & 14647.53 & 8620.24 & 9367.00 & 8607.50 & 114.00 & 11803.52 & 195259.00 & 6413.40 \\
\hline 2008 & 4081.68 & 30933.28 & 3002.65 & 17571.98 & 10358.64 & 9417.00 & 10658.80 & 112.50 & 11768.41 & 244587.00 & 10107.84 \\
\hline 2009 & 4104.65 & 33896.65 & 3226.64 & 18901.83 & 11768.18 & 9470.00 & 12363.00 & 101.20 & 11420.22 & 284086.00 & 11022.22 \\
\hline 2010 & 4155.80 & 39169.92 & 3588.28 & 21238.49 & 14343.14 & 9588.00 & 14620.30 & 118.80 & 10034.37 & 301313.00 & 11832.45 \\
\hline 2011 & 4177.04 & 45361.85 & 3973.85 & 24017.11 & 17370.89 & 9637.00 & 17155.50 & 109.70 & 10077.24 & 318407.00 & 12684.26 \\
\hline 2012 & 4197.84 & 50013.24 & 4281.70 & 25735.73 & 19995.81 & 9685.00 & 19651.90 & 102.50 & 10150.68 & 333603.00 & 11077.78 \\
\hline 2013 & 4218.65 & 55230.32 & 4565.97 & 27442.85 & 23221.51 & 9733.00 & 22294.80 & 105.90 & 10404.74 & 264100.00 & 8194.15 \\
\hline 2014 & 4242.92 & 59426.59 & 4798.36 & 28788.11 & 25840.12 & 9789.00 & 25111.50 & 100.50 & 10601.25 & 264459.00 & 8253.03 \\
\hline 2015 & 4268.06 & 63002.33 & 4979.08 & 29485.90 & 28537.35 & 9847.00 & 27761.40 & 100.10 & 10776.50 & 261849.00 & 8418.04 \\
\hline 2016 & 4311.40 & 68024.49 & 4929.13 & 31343.67 & 31751.69 & 9947.00 & 30645.80 & 102.80 & 10833.95 & 285386.00 & 8884.34 \\
\hline 2017 & 4336.98 & 72634.15 & 4832.71 & 32942.84 & 34858.60 & 10006.00 & 33649.00 & 98.60 & 10938.07 & 327006.00 & 9719.46 \\
\hline 2018 & 4354.75 & 66648.87 & 4950.52 & 27523.67 & 34174.68 & 10047.00 & 33605.00 & 100.50 & 10980.83 & 354019.00 & 10052.20 \\
\hline 2019 & 4364.72 & 71067.53 & 5116.44 & 28310.92 & 37640.17 & 10070.00 & 35770.60 & 112.20 & 11021.39 & 309410.00 & 10166.21 \\
\hline
\end{tabular}

3.Establishment of demand model for cold chain logistics of agricultural products in China's province Shandong

\subsection{Principal component analysis}

Principal component analysis is a dimensionality reduction algorithm that can transform multiple index into a few principal components, which are linear combinations of the original index. Replacing more variables with fewer variables makes the data easier to use, reduces the computational complexity of the algorithm, eliminates some noise data, and makes the results easier to understand.

In view of the large number of selected indexes affecting cold chain logistics forecast of agricultural products in Shandong, and the strong correlation between them, principal component analysis is employed to simplify index with more numbers, so as to facilitate the following model construction. In addition, the factor analysis function of SPSS software was used to carry out standardization and principal component analysis on the ten impact indicators, so as to achieve dimension reduction.

Table 2. Explanation of total variance

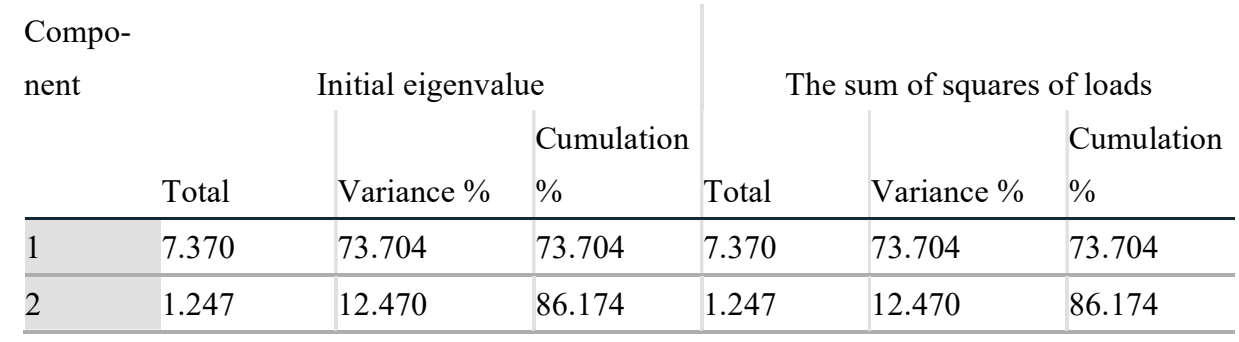




\begin{tabular}{ll|l|l|l|l|l}
\hline 3 & .794 & 7.940 & 94.114 & & & \\
\hline 4 & .480 & 4.804 & 98.918 & & & \\
\hline 5 & .071 & .714 & 99.632 & & & \\
\hline 6 & .022 & .220 & 99.853 & & & \\
\hline 7 & .012 & .119 & 99.972 & & & \\
\hline 8 & .003 & .027 & 99.999 & & & \\
\hline 9 & .000 & .001 & 100.000 & & & \\
\hline 10 & $7.295 \mathrm{e}-15$ & $7.295 \mathrm{e}-14$ & 100.000 & & & \\
\hline
\end{tabular}

It is obvious that there are two principal components with an eigenvalue greater than 1 . When extracting the two, the cumulative contribution rate reached $86.17 \%$, which indicated that it covered more than $85 \%$ of the original variable information and enjoyed a good effect. According to "Fig. 1", it is reasonable to extract the two components.

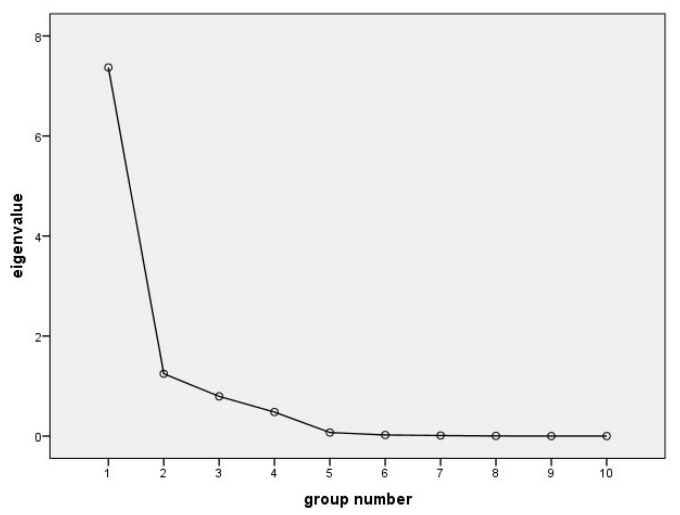

Fig. 1. Gravel for principal component analysis.

Table 3. Matrix of component score coefficients

\begin{tabular}{|c|c|c|}
\hline & \multicolumn{2}{|c|}{ Component } \\
\hline & 1 & 2 \\
\hline Regional GDP (100 million yuan) & .134 & -.103 \\
\hline The added value of the primary industry (100 million yuan) & .134 & -.020 \\
\hline The added value of the secondary industry (100 million yuan) & .133 & -.024 \\
\hline The added value of the tertiary industry (100 million yuan) & .130 & -.168 \\
\hline $\begin{array}{l}\text { Permanent residents population at the end of the year }(10,000 \text { peo- } \\
\text { ple) }\end{array}$ & -.133 & -.076 \\
\hline Total retail sales of consumer goods (100 million yuan) & .130 & -.159 \\
\hline Production price index of agricultural products & -.054 & .519 \\
\hline The output of fruits and vegetables ( 10,000 tons $)$ & -.061 & -.409 \\
\hline Freight volume of Shandong Province (10,000 tons) & .123 & .245 \\
\hline Turnover (million tons/km) & .094 & .484 \\
\hline
\end{tabular}

a. Extraction method: principal component analysis.

Table 3 shows the relationship between principal components and each influencing factor. $F_{1}$ and $F_{2}$ respectively represent the two principal components extracted, and it can be concluded that: 
$\mathrm{F} 1=0.134 \mathrm{X}_{1}+0.134 \mathrm{X}_{2}+0.133 \mathrm{X}_{3}+0.130 \mathrm{X}_{4}+0.133 \mathrm{X}_{5}+0.130 \mathrm{X}_{6}-0.054 \mathrm{X}_{7}-0.061 \mathrm{X}_{8}+0.123 \mathrm{X}_{9}+0.094 \mathrm{X}_{10}$

$F 2=-0.103 X_{1}-0.020 X_{2}-0.024 X_{3}-0.168 X_{4}-0.076 X_{5}-0.159 X_{6}+0.519 X_{7}-0.409 X_{8}+0.245 X_{9}+0.484 X_{10}$

In SPSS, the standardized scores of two principal components are calculated by component score coefficient in Table 4.

Table 4. Component score

\begin{tabular}{llllllllll}
\hline Year & 2003 & 2004 & 2005 & 2006 & 2007 & 2008 & 2009 & 2010 & 2011 \\
\hline F1 & -1.67117 & -1.54841 & -1.25106 & -0.99801 & -1.03035 & -0.60076 & -0.23983 & 0.028 & 0.37284 \\
F2 & -0.65351 & -0.26168 & -0.79649 & -0.14402 & -0.15746 & 0.4948 & 0.00337 & 2.63746 & 1.90062 \\
\hline Year & 2012 & 2013 & 2014 & 2015 & 2016 & 2017 & 2018 & 2019 \\
\hline F1 & 0.56321 & 0.46184 & 0.65012 & 0.77493 & 0.96865 & 1.23368 & 1.16652 & 1.11979 \\
F2 & 0.84915 & 0.04558 & -0.6762 & -0.93328 & -0.71974 & -0.99468 & -0.6684 & 0.07447
\end{tabular}

\subsection{Time series model prediction}

The time series prediction is to make an analogy or extension according to the development process, direction and trend reflected in the series by compiling and analyzing it, so as to predict the level that may be reached in the next period or in the following years.

The expert modeler in SPSS was adopted to build a time series model to predict the principal component data from 2003 to 2019. The modeler will automatically find the best fitting model for each dependent sequence, and take into account exponential smoothing model and ARIMA. The results are as follows in Table 5:

Table 5. Time series model

\begin{tabular}{ll}
\hline Model ID REGR factor score 1 for analysis 1 Model__ & $\operatorname{ARIMA}(0,1,0)$ \\
\hline Model ID REGR factor score 2 for analysis 2 Model_2 & $\operatorname{ARIMA}(1,0,0)$ \\
\hline
\end{tabular}

ARIMA $(0,1,0)$ and ARIMA $(1.0,0)$ are selected by the modeler as time series prediction models respectively. The ARIMA model regards data sequence of the predicted object over time as a random sequence and adopts certain mathematical model to describe the sequence. The prediction results of SPSS on the two principal components are as follows in Table 6:

Table 6. Time series prediction results

\begin{tabular}{llll}
\hline Model & 2020 & 2021 & 2022 \\
\hline REGR factor score 1 for analysis 1-Model_11.29422 & 1.46866 & 1.64309 \\
REGR factor score 2 for analysis 2-Model_20.04396 & 0.02595 & 0.01532
\end{tabular}

\subsection{Multiple linear regression}

The method of multiple regression analysis and prediction refers to the establishment of a model for prediction through the analysis of two or more independent variables and one dependent variable. SPSS was adopted to establish the multiple linear regression equation of total demand $\mathrm{Y}$ and principal components $\mathrm{F}_{1}$ and $\mathrm{F}_{2}$ for cold chain logistics of agricultural products in Shandong. The results are as follows in Table 7:

Table 7. Linear regression coefficient 


\begin{tabular}{|c|c|c|c|c|c|c|c|}
\hline \multirow[b]{2}{*}{ Model } & \multicolumn{2}{|c|}{$\begin{array}{l}\text { Unstandardized } \\
\text { cients }\end{array}$} & \multirow{2}{*}{$\begin{array}{l}\text { Standard- } \\
\text {-ized coeffi- } \\
\text { cient } \\
\text { - }\end{array}$} & \multirow[b]{2}{*}{$\mathrm{T}$ value } & \multirow[b]{2}{*}{$\begin{array}{l}\text { Signifi- } \\
\text { cance }\end{array}$} & \multicolumn{2}{|c|}{$\begin{array}{l}\text { B's } 95.0 \% \text { confidence in- } \\
\text { terval }\end{array}$} \\
\hline & B & $\begin{array}{l}\text { Standard er- } \\
\text { ror }\end{array}$ & & & & The bottom & The cap \\
\hline 1 (constant) & 4167.757 & 5.571 & & 748.059 & .000 & 4155.807 & 4179.706 \\
\hline $\begin{array}{l}\text { Regr factor score } 1 \text { for analysis } \\
1\end{array}$ & is 132.141 & 5.743 & 0.983 & 23.009 & .000 & 119.824 & 144.458 \\
\hline $\begin{array}{l}\text { Regr factor score } 2 \text { for anal- } \\
\text { ysis } 1\end{array}$ & $1--12.745$ & 5.743 & -0.095 & -2.219 & .043 & -25.062 & -.428 \\
\hline
\end{tabular}

b. Dependent variable: demand for cold chain logistics of agricultural products (10,000 tons)

The principal component regression equation obtained from the above solution is as follows:

Standardization equation: $\mathrm{Y}=0.983 \mathrm{~F}_{1}-0.095 \mathrm{~F}_{2}+\mathrm{C}$

Unstandardization equation: $\mathrm{Y}=132.141 \mathrm{~F}_{1}-12.745 \mathrm{~F}_{2}+\mathrm{C}$

According to the previous data, the estimated constant c $=4167.757$

Further analysis of the output table of multiple regression model showed that the model's fitting $\mathrm{R}^{2}$ was 0.987 , and the adjusted $\mathrm{R}^{2}$ was $0.985>0.9$, indicating a good model fitting in Table 8 .

Table 8. Linear regression error

\begin{tabular}{lllll} 
Model & $\mathrm{R}$ & $\mathrm{R}^{2}$ & Adjusted $\mathrm{R}^{2}$ & Error of standard estimate \\
\hline 1 & $0.994^{\mathrm{a}}$ & 0.987 & 0.985 & 15.4042894300 \\
\hline
\end{tabular}

By substituting the predicted principal component value obtained from time series prediction into the multiple regression equation, the predicted value of cold chain demand for agricultural products in Shandong in the next three years can be obtained in Table 9:

Table 9. forecast of the regression equation

\begin{tabular}{ll}
\hline Time & $\begin{array}{l}\text { Y }(10,000 \\
\text { tons })\end{array}$ \\
\hline 2018 & 4354.75 \\
2019 & 4364.71 \\
2020 & 4338.22 \\
2021 & 4361.50 \\
2022 & 4384.68
\end{tabular}

\subsection{BP neural network prediction}

BP neural network, one of the most widely used neural network models, is a multi-layer feedforward network trained by error inverse propagation algorithm. It can learn and store mapping relation of a large number of input and output patterns without revealing the mathematical equation describing such relation in advance. It takes the steepest descent 
and continuously adjusts the weights and thresholds of the network through back propagation to minimize the sum of squared errors.

However, rather than a simple linear system, the demand for cold chain logistics of agricultural products is affected by many factors with complex relationships among each other. In order to make the results of cold chain logistics demand prediction model of Shandong agricultural products more scientific and accurate, BP neural network prediction model was established on the basis of principal component analysis.

The neural network model enjoys two input layers, namely two principal components extracted after principal component analysis, one output layer, and ten neurons in Fig.2.

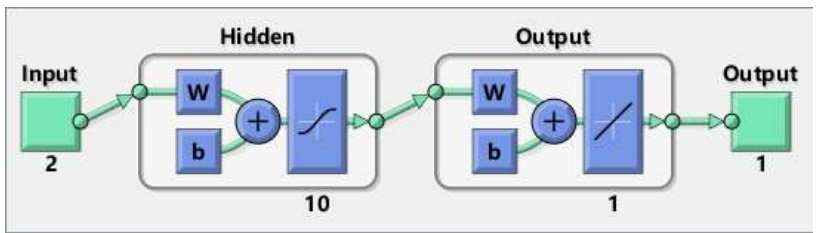

Fig. 2. Neural network model.

In order to ensure the accuracy of BP neural network model and improve the efficiency of neural network, the data are divided into training set, verification set and test set. Training set is the data sample used for model fitting, verification set is the sample set left aside during model training, while test set is used to evaluate the generalization ability of the final model. Training set, verification set and test set account for $70 \%, 15 \%$ and $15 \%$ respectively.

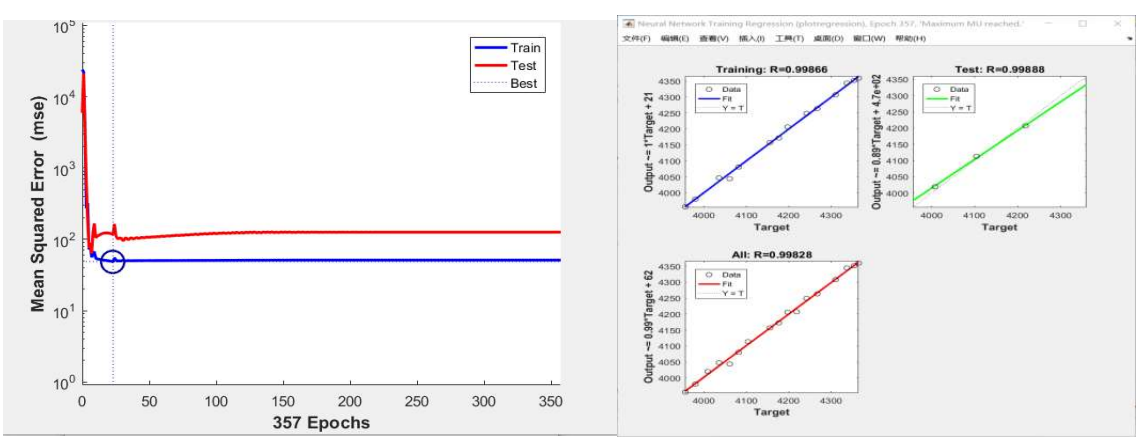

Fig. 3. Iteration of neural networks.

The number of iterations obtained by multiple training is 357, with a small error, and the training effect of neural network model is good. The predicted value of cold chain logistics demand for agricultural products in Shandong obtained by Matlab is as follows in Table 10:

Table 10. Neural network prediction results

\begin{tabular}{ll}
\hline Time & Y (10,000 tons $)$ \\
\hline 2018 & 4351.5 \\
2019 & 4359.5 \\
2020 & 4404.04 \\
2021 & 4447.62 \\
2022 & 4489.54
\end{tabular}


4. Construction of combined prediction model

The combined prediction model can combine multiple single prediction models through certain combination strategies or methods, which makes up for the deficiency of single model prediction in some aspects, and improves the prediction ability of combined model through scientific and reasonable way. In reality, the cold chain logistics system of agricultural products is more complex and influenced by many factors. It is often one-sided to make prediction through a single prediction model. Therefore, the combined prediction model of multiple regression and neural network was adopted to comprehensively consider the influencing factors of cold chain logistics of agricultural products and reduce the one-sidedness of single prediction model, in a bid to achieve better prediction effect[22].

The combined prediction model based on multiple linear regression and BP neural network is more scientific and reasonable. It is as simple, scientific and reasonable as multiple linear regression model, and as accurate as BP neural network prediction with small error, which improves reliability and accuracy and contributes to the accuracy and rationality of the combined model prediction.

There are many methods to determine the weight of combined model, among which the simple and widely used are arithmetic mean method, reciprocal method of variance, reciprocal method of mean square error, simple weighted average method, etc. The arithmetic mean method, also known as equal weight average method, is based on the principle that all single prediction models are treated equally, so that the weight coefficients of each method are equal. The reciprocal method of variance calculates the weight coefficient according to square sum of prediction error. The larger the value is, the lower the prediction accuracy of the prediction model will be, and the smaller the weight coefficient assigned to the prediction model will be. On the contrary, the larger the weight coefficient will be. The reciprocal method of mean square error is also based on the principle that the greater the value of the sum of squared errors of a single prediction model, the smaller the weighted coefficient should be. The simple weighted average method first sorts the squares of the prediction errors of each single item model. The more closely the order is to the previous single item prediction model, the smaller the weighted coefficient should be in the combined prediction.

Table 11. Comparison of combined models

\begin{tabular}{|c|c|c|c|c|c|}
\hline \multirow{2}{*}{ Actual value } & \multirow{2}{*}{ Regression prediction } & \multirow{2}{*}{$\mathrm{BP}$ prediction } & \multirow{2}{*}{ Reciprocal method of variance } & \multicolumn{2}{|c|}{ Reciprocal method of mean Simple weighted average } \\
\hline & & & & square error & method \\
\hline 3955.12 & 3955.26 & 3956.4 & 3956.26 & 3956.09 & 3956.02 \\
\hline 3978.96 & 3966.48 & 3980.6 & 3978.87 & 3976.76 & 3975.89 \\
\hline 4008.43 & 4012.59 & 4020.2 & 4019.27 & 4018.13 & 4017.66 \\
\hline 4034.87 & 4037.71 & 4047.7 & 4046.47 & 4044.98 & 4044.37 \\
\hline 4060.01 & 4033.61 & 4044.2 & 4042.90 & 4041.32 & 4040.67 \\
\hline 4081.68 & 4082.07 & 4080.3 & 4080.52 & 4080.78 & 4080.89 \\
\hline 4104.65 & 4136.02 & 4113.3 & 4116.09 & 4119.49 & 4120.87 \\
\hline 4155.80 & 4137.84 & 4157.4 & 4155.00 & 4152.07 & 4150.88 \\
\hline 4177.04 & 4192.80 & 4172.0 & 4174.56 & 4177.66 & 4178.93 \\
\hline 4197.84 & 4231.36 & 4206.5 & 4209.55 & 4213.27 & 4214.79 \\
\hline 4218.65 & 4228.20 & 4206.9 & 4209.52 & 4212.70 & 4214.00 \\
\hline 4242.92 & 4262.28 & 4249.3 & 4250.89 & 4252.84 & 4253.63 \\
\hline 4268.06 & 4282.05 & 4263.5 & 4265.78 & 4268.55 & 4269.68 \\
\hline 4311.40 & 4304.93 & 4307.7 & 4307.36 & 4306.95 & 4306.78 \\
\hline
\end{tabular}




\begin{tabular}{llllll}
4336.98 & 4343.45 & 4343.8 & 4343.76 & 4343.71 & 4343.68 \\
4354.75 & 4330.42 & 4351.5 & 4348.91 & 4345.76 & 4344.47 \\
4364.72 & 4314.78 & 4359.5 & 4354.01 & 4347.32 & 4344.59 \\
\hline \multicolumn{2}{l}{ Mean absolute error 16.18} & 6.49 & 6.77 & 7.71 & 8.32 \\
\hline Error \% & $0.384 \%$ & $0.156 \%$ & $0.163 \%$ & $0.185 \%$ & $0.199 \%$ \\
\hline \multicolumn{2}{l}{$\begin{array}{l}\text { The sum of squared } \\
\text { errors }\end{array}$} \\
\hline
\end{tabular}

The table11 above shows the difference between the combined prediction models employing different methods to determine the weights. As for mean absolute error and the sum of squared errors, the reciprocal method of variance enjoys the least error, followed by the reciprocal method of mean square error and the simple weighted average method. Therefore, the combined model works best with the reciprocal method of variance.

5. Conclusions

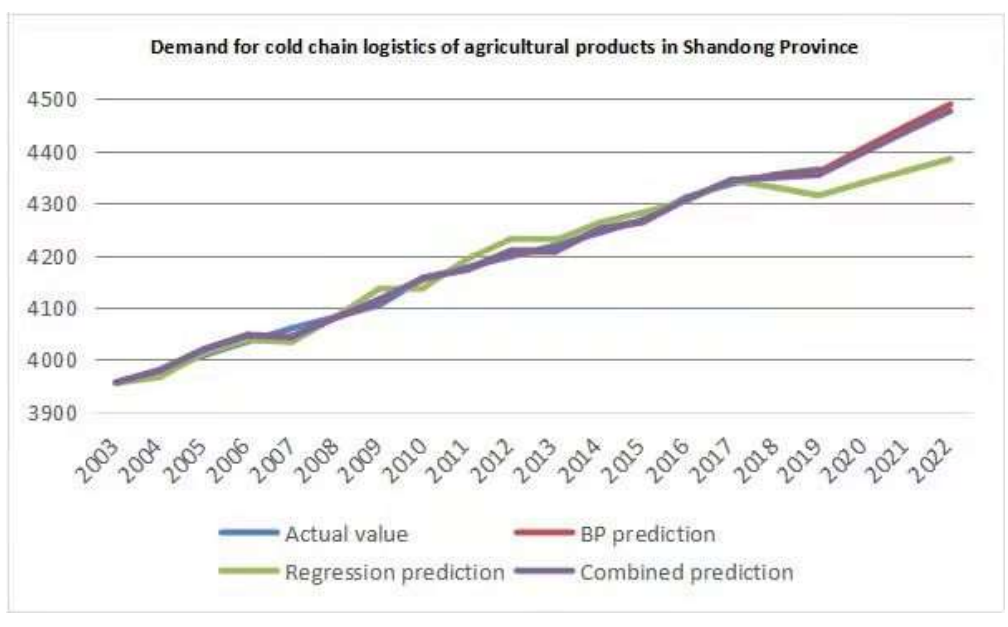

Fig. 4. Demand for cold chain logistics of agricultural products in Shandong Province.

In this paper, SPSS, Matlab and other software are employed to combine principal component analysis and time series prediction. On this basis, multiple linear regression and neural network are adopted to predict the cold chain logistics demand of agricultural products in Shandong province more scientifically and accurately in Fig.4. As for the selection of data index, based on existing research and practice and numerous influencing factors for cold chain logistics of agricultural products in Shandong, demand forecast index system is established from different angles, and principal component analysis, a common dimension reduction method, is taken to transform data index with more category to principal components with fewer number, which benefits multiple linear regression and neural network prediction. The combined model of multiple linear regression and neural network is scientifically simple and accurate. The results of all prediction models reveal that the demand for cold chain of agricultural products in Shandong mounts obviously during 2020-2022, which indicates an opportunity for development of cold chain logistics of agricultural products here, as well as strong driving force.

Funding: This research was funded by Cooperative education project of the Ministry of Education, grant number 201901156027.

Acknowledgments: This work was partially supported by Shandon Finance and Economic University. 
Conflicts of Interest: The authors declare no conflict of interest.

\section{References}

[1] Ban Ran. Cost-benefit Analysis of Cold Chain Logistic to Agricultural Products [J]. Journal of Technical Economics \& Management. 2018, 269(12): 30-4.

[2] Wang Fengli, Wang Jiamin, Bi Ran. Research on Development Status and Countermeasures of Cold Chain Logistics Industry of Agriculture Products in Shandong Province [J]. Logistics Engineering and Management, 2019, 041(007): 28-9,40. (in Chinese)

[3] National Development and Reform Commission. Planning for Cold Chain Logistics Development of Agricultural Products [J]. Commercial Research. 2010, 11): 129. (in Chinese)

[4] Wang Xiaoping, Yan Fei. Forecast of cold chain logistics demand for agricultural products in Beijing based on neural network [J]. Guangdong Agricultural Sciences, 2018, 45(06): 126-34. (in Chinese)

[5] Huang Liwei. Research on the Problems in Cold Chain Logistics Development of Agricultural Products and the Countermeasures [D]. Chinese Academy of Agricultural Sciences, 2007. (in Chinese)

[6] Xu Qian, Zhao Min. Research on the Development Status of Agricultural Products Supply Chain in Shandong Province [J]. Market Modernization, 2019, 000(002): 30-2. (in Chinese)

[7] He Guohua. Forecast of Regional Logistics Requirements and Application of Grey Prediction Model [J]. Journal of Beijing Jiaotong University(Social Sciences Edition), 2008, 01): 33-7. (in Chinese)

[8] Yan Juan. Application of Logistics Demand Forecasting Based on Grey Neural Network [J]. Computer Simulation, 2011, 028(7): 200-3. (in Chinese)

[9] Wang Shaoran. Research on cold chain logistics demand forecast of fresh agricultural products [D]. Xi'an Polytechnic University, 2017. (in Chinese)

[10] Bogataj M, Bogataj L, Vodopivec R. Stability of perishable goods in cold logistic chains [J]. 2005, 93-94(none): 345-56.

[11] Montanari R. Cold chain tracking: a managerial perspective [J]. Trends in Food ence \& Technology, 2008, 19(8): 425-31.

[12] Ran B. Cost-benefit Analysis of Cold Chain Logistic to Agricultural Products [J]. Journal of Technical Economics \& Management, 2018,

[13] Likar K, J Nik M. Cold chain maintaining in food trade [J]. Food Control, 2006, 17(2): 108-13.

[14] Kim W R, Aung M M, Chang Y S, et al. Freshness Gauge based cold storage management: A method for adjusting temperature and humidity levels for food quality [J]. Food Control, 2015, 47(510-9.

[15] Bin Z, Amp S V. Research on Layout Planning of Agricultural Products Cold Chain Logistics Park [J]. 2019,

[16] Fanlk, Constantatos. The Combination of forecasts [J]. Transportion Research Part E: Logistics and Transportion Review Volume, 2000, 11(3)(173-80.

[17] Flsieh. Developing green supply chain ma nagement strategy of hotel-centered in vegetable and fruit purchasing and recycling [J]. IEEE International Conference on Industrial Engineering and Enginee- ring Management, 2011, 1153-450.

[18] Nuzzolo A, Comi A, Rosati L. City logistics long-term planning: simulation of shopping mobility and goods restocking and related support systems [J]. International Journal of Urban Sciences, 2014,

[19] EKsoz C, Mansoun S A, Bourlakis M. Collaborative forecasting in the food supply chain:A conceptual framework [J]. 2014, $12(158)(120-35$.

[20] Wang Xiaoping, Peng Wenkai, Lu Huaiyu. Forecast of Cold Chain Logistics Demand for Agricultural Products in Beijing Based on Support Vector Machine Model [J]. Hubei Agricultural Sciences, 2018, v.57; No.612(15): 90-6. (in Chinese)

[21] Xu Xuan. Research on the status quo, problems and countermeasures of the cold chain logistics development of agricultural products in Yancheng [D]. 2015. (in Chinese) 
[22] Feng Yongyan. Research on Demand Forecast of Agricultural Products Cold Chain Logistics in Beijing [D]. 2016. (in Chinese) 